\title{
Intervention Strategies to Improve Compliance with Medical Regimens by Ambulatory Hemodialysis Patients
}

\author{
K. Michael Cummings, ${ }^{1}$ Marshall H. Becker, ${ }^{2}$ John P. Kirscht, ${ }^{2}$ \\ and Nathan W. Levin ${ }^{3}$
}

Accepted for publication: September 17, 1980

\begin{abstract}
This research examined the relative efficacies of three intervention strategies designed to increase compliance to medical regimens in a group of ambulatory hemodialysis patients. The interventions examined included behavioral contracting (with or without the involvement of a family member or friend) and weekly telephone contacts with patients. Compliance was assessed with regard to following dietary restrictions and limiting fluid intake. Data were collected from 116 patients drawn from two outpatient clinics. Within clinics, patients were randomly assigned either to an intervention program or to a control group. The study employed a pretest-posttest control group design. Patients were interviewed before the intervention programs began $\left(T_{1}\right)$, after a 6-week intervention period $\left(T_{2}\right)$, and 3 months after completion of the intervention period $\left(T_{3}\right)$. Results showed that the interventions achieved substantial reductions in patients' serum potassium levels and in weight gains between dialysis treatments between $T_{1}$ and $T_{2}$. In general, however, these program effects tapered off to preintervention levels between $T_{2}$ and $T_{3}$. The findings thus indicate a need for long-term intervention programs.
\end{abstract}

KEY WORDS: hemodialysis; compliance; health beliefs.

This work was funded by a grant from the Michigan Department of Public Health.

'Department of Community Medicine, Wayne State University, Detroit, Michigan 48202. ${ }^{2}$ Department of Health Behavior and Health Education, School of Public Health, University of Michigan, Ann Arbor, Michigan 48109.

${ }^{3}$ Division of Nephrology, Henry Ford Hospital, Detroit, Michigan 48202. 


\section{INTRODUCTION}

While the problem of adherence to medical regimens is now widely recognized and studied, there is still relatively little known about the determinants of patient adherence and about the effectiveness of different interventions to modify adherence behavior. The present study had two major purposes: (1) assessment of the relationship of health beliefs to adherence behavior in a group of hemodialysis patients and (2) examination of the relative effectiveness of three intervention strategies designed to increase compliance to diet and fluid restrictions in a group of ambulatory hemodialysis patients. The three intervention programs tested included (1) behavioral contracting, (2) behavioral contracting with a family member or friend involved in writing the contract together with the patient and a nurse from the clinic, and (3) weekly telephone contacts with patients by clinic nurses.

From a theoretical perspective, the interventions were designed to cover a range of strategies for change, including persuasion, reward, and social support. The two contracting interventions were viewed as behavior modification strategies, whereas the weekly telephone contact intervention was designed to modify patients' health beliefs and, through this mechanism, improve compliance. Behavior modification approaches have been reported to be effective in dealing with compliance problems related to weight reduction (Penick et al., 1971; Stunkard, 1972) and hypertension control (Steckel and Swain, 1977). However, questions are often raised concerning the effectiveness of these approaches in helping patients to maintain targeted behaviors once the inducements for behavior change are removed.

Several investigators have been interested in the effects on healthrelated behavior of attempts to modify beliefs (Haefner and Kirscht, 1970; Kirscht et al., 1978; Weisenberg et al., 1980). Belief change strategies are based on the assumption that specific beliefs are the most important antecedents of decisions to act and that modification of such beliefs will result in desired alterations in behavior. Recent evidence for the utility of a health belief framework in relation to compliance behavior among hemodialysis patients is offered by Hartman and Becker (1978), who found adherence to be associated with patients' perceptions of the probability of illness occurring as a result of noncompliance, the severity of these conditions should they occur, the value of following the prescribed regimen, and the barriers which interfere with compliance. Evidence for the effectiveness of belief change approaches to behavior change is mixed (Haefner and Kirscht, 1970; Weisenberg et al., 1980). However, it can be argued that, in contrast to behavior modification interventions, a belief change approach might be better suited to effecting long-term behavior change because it emphasizes having people internalize the cognitive rationale for modifying their behavior. Therefore, in this study, it was hypothesized that long-term compliance 
levels would be higher for patients in the weekly telephone contact intervention than for patients in either of the two contracting interventions because of the telephone contact's focus on belief change.

Dietary management of patients on hemodialysis is a critical aspect of the overall treatment plan for renal failure. The major objective of such managment is to assist hemodialysis treatments by reducing the amounts of urea, creatinine, and electrolytes (especially potassium, sodium, and phosphate) which must be excreted (Anderson et al., 1973; Burton, 1974). Abuse of dietary (diet and fluid) restrictions can result in a buildup of toxic fluids and metabolic end products in the blood stream which may lead to cardiovascular problems, uremic symptomatology, and even death. However, despite the adverse consequences associated with poor compliance, there is substantial evidence of considerable abuse of dietary restrictions among hemodialysis patients (Retan and Lewis, 1965; Shea et al., 1965; Pendras and Erickson, 1966; Meldrum et al., 1968; Abram et al., 1971; DeNour and Czaczkes, 1972; Hickey, 1972; Neff et al., 1973; Borkman, 1976; Blackburn, 1977; Hartman and Becker, 1978).

\section{METHOD}

\section{Design and Subjects}

The study employed a pretest-posttest control group design. Patients were interviewed at three points in time; before the intervention program began $\left(T_{1}\right)$, immediately following completion of the 6-week intervention period $\left(T_{2}\right)$, and 3 months after completion of the intervention period $\left(T_{3}\right)$. Interviews were conducted by trained interviewers while patients were on dialysis. The interview included questions concerning the patient's treatment history (e.g., length of time receiving dialysis treatments, eligibility for kidney transplant), beliefs about susceptibility to sequelae of noncompliance with dietary and fluid restrictions, perceptions of the severity of noncompliance sequelae should they occur, beliefs about likely benefits and barriers associated with the prescribed treatment regimen, and personal characteristics.

Dietary compliance was evaluated by examining patients' potassium levels, and fluid limit adherence was assessed by examining patients' weight gains between dialysis treatments. These data were collected routinely each time the patient came in for dialysis.

The study was conducted in two outpatient dialysis clinics located in Southeastern Michigan. The study group consisted of 120 patients $(72 \%$ of the total patient population from both clinics). Patients were accepted into 
the study if they had no unusual physical or mental disabilities which could be expected to interfere with their participation in an interview, were between 18 and 80 years of age, and had been receiving dialysis treatments for a minimum of 3 months. Within clinics, patients were randomly assigned to either an intervention program or a control group.

A comparison of patient characteristics between clinics was carried out to determine the appropriateness of pooling data from the two clinic sites. Two-sample $t$-tests and chi-square analyses were performed on baseline measures of sociodemographic variables, medical history variables, health belief variables, and compliance levels. The results of these analyses indicated no statistically significant differences at the $10 \%$ level or better between patients from the clinic sites.

Of the 120 potential study participants, 4 refused to be interviewed at $T_{1}(97 \%$ response rate). Twenty of the 116 remaining patients did not participate in the second round of interviewing $(N=96)$. At $\mathrm{T}_{2}$ the behavioral contract, behavioral contract with a family member or friend, weekly telephone contact, and control groups contained $24,19,28$, and 25 subjects, respectively $(N=96)$. An additional 9 patients did not participate in the third round of interviewing. At $\mathrm{T}_{3}$ the behavioral contract, behavioral contract with a family member or friend, weekly telephone contact, and control groups contained $22,18,23$, and 24 subjects, respectively $(N=87)$.

Analyses of dropouts at $T_{2}, T_{3}$, and combined (i.e., $T_{2}$ and $T_{3}$ ) revealed that attrition rates, potassium levels, weight gains, and belief scores did not differ significantly across experimental groups and therefore could not account for any group differences observed.

Patients ranged in age from 21 to 76 years (mean, 54.8). Of the initial 116 study patients, $54 \%$ were male and half were white. The median educational level achieved was high school graduation. Median family income was between $\$ 10,000$ and $\$ 10,999$ per year, with $16 \%$ receiving less than $\$ 5,000$ annually. Most of the participants $(67 \%)$ were married, with $9 \%$ never married and the remainder widowed, divorced, or separated. Eight patients $(7 \%)$ reported that they lived alone. Seventy-five percent of the sample indicated that they were currently employed either full time or part time. Of those individuals who were not currently employed, $72 \%$ indicated that they had stopped working because of their illness.

The average length of time the study patients had been receiving dialysis treatment was 29 months; most patients $(87 \%$ ) were receiving dialysis treatments three times per week. Only a quarter of the patients $(N$ $=28$ ) indicated that they expected to have a kidney transplant in the future.

\section{Experimental Groups}

Behavioral Contract. The "contract only" intervention consisted of four steps: (1) identifying a behavior or set of behaviors to be targeted for 
change in the contract; (2) negotiating with the patient a timetable for the accomplishment of the specified behaviors (e.g., by the next dialysis treatment, by the end of 6 weeks), how degree of accomplishment should be evaluated (e.g., turn in chart of weight gains), what rewards would be received for appropriate behaviors, and when the patient would be rewarded; (3) writing out a formal agreement which was subsequently signed by both the nurse and the patient; and (4) maintaining a record of each patient's progress, so that the patient was rewarded according to the terms of the contract.

Contracts were formulated and negotiated by nurses from the dialysis clinics. Each contract lasted 6 weeks. After explaining the contracting process, and working out a tentative contract agreement, the nurse negotiated with the patient a timetable indicating the times by which specified behaviors should be accomplished, how the behaviors would be evaluated, and when the patient would be rewarded. The rewards were state lottery tickets.

Nurses were instructed to establish a reward schedule so that patients would have both long- and short-range goals toward which to work.

If a patient was experiencing great difficulty meeting the terms of the agreement, the nurse was instructed to renegotiate the contract, by adding to (or subtracting from) items in the contract and/or changing the reward schedule to make the rewards easier (or more difficult) for the patient to attain. An example of the contract form used in the study is presented in Fig. 1. A file was created for every patient in the contract intervention, enabling each patient's progress to be monitored by any member of the clinic staff. Patients received feedback about their progress from one of the nurses each time they returned to the clinic for dialysis treatments.

Behavioral Contract with a Family Member or Friend. The intervention "behavioral contract with a family member or friend" consisted of the same procedures as the contract only intervention, except that a third person selected by the patient (preferably someone from the patient's household) participated in the contract agreement along with the patient and the nurse. A letter from the clinic (signed by the nurse) was sent to this person inviting him/her to participate with one of the clinic nurses in a special education program dealing with various aspects of the patient's medical treatments. The letter stated that, for the patient to be eligible to participate in the program, the selected family member or friend must accompany the patient to the clinic at least once to meet with the nurse. Only when both the patient and the selected family member or friend were present at the clinic was the formal contract written. In writing the agreements, nurses were instructed to include activities that the family member or friend could undertake for the patient (e.g., a weekly menu for the patient might be created and implemented).

Weekly Telephone Contacts. The "telephone contact" intervention involved three activities: (1) gathering information from patients regarding problems they might be having in following their treatment instructions; (2) providing information to patients about such things as the potential negative 
HEALTH CARE AGREEMENT

We, Jane Doe and Doris Evans agree to the following actions to help assure improvement of Jane Doe's health.

(1) I agree to gain not more than $3 \mathrm{~kg}$. of fluid weight gain between dialysis treatments, for which 1 'll receive 3 points.

(2) I agree to follow recommended dietary restrictions so that my pre $\mathrm{K}+$ level is 5.5 or below, for which 1 will receive 3 points.

(3) I agree to keep a diary of the amount of fluid I drink, time taken, and type on a weekly basis for which 1 will receive 10 points on

(4) Saturday, if completed.

(5)

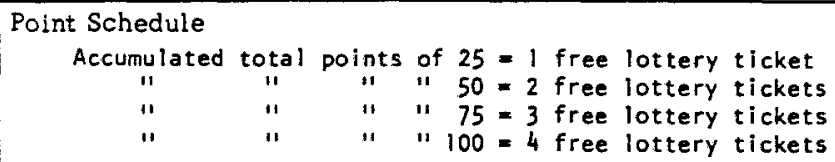

It is understood that this agreement can be revised at a later date. The terms of the agreement will be reviewed and revision made, if necessary, on Max 3.1979

We agree to follow and abide by the actions outlined above.

Jane Doe
Signed
Doris Evans
Signed

$\frac{4-12-79}{\text { Date }}$
D-12-79
Date
Date

Fig. 1. Sample contract agreement between patient and nurse.

health consequences of not adhering to therapy, the benefits to be derived from following treatment instructions, and things the patients could do to achieve better compliance; and (3) providing verbal support to patients for maintaining proper adherence to treatment. The telephone contacts were made by nurses from the dialysis clinics. Patients were contacted once a week for 6 weeks, and each call lasted about $11 \mathrm{~min}$.

Various types of messages were developed for use by the nurses. The messages were more or less standard in content but tailored to the particular 
patient's needs and recent medical experience. In addition, the nurses also provided oral reinforcement to patients for any examples of appropriate compliance behaviors. For example: "Fine. I'm glad to see that you have reduced your weight gains." "Good. I think it would be helpful if you keep a weekly menu." "Your potassium levels have been excellent for the last week."

Nonintervention Control. The control condition consisted simply of the absence of special interventions. Patients assigned to this condition received routine medical care, which included coming into the clinic for dialysis treatments two or three times a week. As a part of usual clinic procedure, patients were given information about their blood levels and weight gains between treatments. In addition, if a patient was experiencing difficulty complying with the treatment regimen (e.g., exhibited high weight gain or unusually high blood levels), a nurse or a dietician would counsel the patient.

\section{Patient Compliance}

The patient's mean serum potassium level (SPL) was used as a measure of dietary compliance. The mean SPL at $T_{1}$ was based on six observations, three taken before and three taken after the initial interview. At $T_{2}$, the mean SPL was based upon all SPLs recorded in the patient's medical chart during the 6-week intervention period (average number of observations $=16$ ). The mean SPL at $T_{3}$ was computed from all chartrecorded SPLs during the 12 weeks following completion of the intervention period (average number of observations $=29$ ).

The patient's mean weight gain (WG) between dialysis treatments was used as a measure of compliance with the regimen limiting fluid intake. The mean WG at $T_{1}$ is based on six observations, three taken before and three taken after the baseline interview. At $T_{2}$, the mean $W G$ is based upon all WGs recorded in the patient's medical chart during the 6-week intervention period (average number of observations $=16$ ). The mean $\mathrm{WG}$ at $\mathrm{T}_{3}$ is based on all chart-recorded WGs for the 12 weeks following completion of the intervention period (average number of observations $=33$ ). Weight gains are computed by subtracting each patient's predialysis weight from his/her last treatment's postdialysis weight.

\section{Measures of Health Beliefs}

Items pertaining to particular health belief dimensions were combined into indices on the basis of content and interitem relationships. The major indices included perceived susceptibility to sequelae of noncompliance with dietary restrictions (e.g., "What chance do you think there is you would 
have weak and tired muscles?'”) and sequelae of noncompliance with fluid intake limits (e.g., "What chance do you think there is you would have shortness of breath?'); perceived severity of sequelae associated with noncompliance with dietary restrictions (e.g., "How serious do you think it would be if you were to get high levels of potassium in your blood?") and severity of sequelae associated with noncompliance with fluid intake limits (e.g., "How serious do you think it would be if you were to store up too much fluid in your body between dialysis treatments?'); beliefs about the likely benefits of the diet (e.g., "How much do you think the diet helps to prevent you from becoming weak and tired?") and the fluid limit (e.g., "How much do you think limiting the amount of fluid you drink prevents you from having shortness of breath?'"); and barriers to following the diet (e.g., "Did you ever not follow the diet because you don't always have time to prepare special meals?") and barriers to limiting fluid intake (e.g., "Did you ever not stick to your fluid limit because you felt the fluid limit was too strict?").

The susceptibility, severity, and benefit items were measured using seven-point Likert scales. Indices were constructed by computing mean scores. Estimates of internal-consistency reliability for these indices range from 0.57 to 0.92 , with the indices of perceived benefits and of perceived severity yielding the highest and lowest levels of consistency respectively. The "barriers" items were coded either "yes" or "no"; these indices were constructed by adding the number of "yes" responses to items assessing factors interfering with a patients' adherence to a particular regimen (i.e., seven items concerning barriers to compliance with the diet and five items involving barriers to compliance with fluid restrictions).

Table I shows the means, ranges, and standard deviations for each of the dependent variables across the three measurement periods.

\section{RESULTS}

\section{Analysis Plan}

A check of the baseline equivalence of the experimental groups revealed a significant difference between groups on patients' average WG $[F(1,92)=$ 5.24, $P<0.05$ ]; a similar (but not statistically significant) difference between experimental groups was found for patients' average SPL. In both cases, patients in the weekly telephone contact group were less compliant than were patients in the other experimental groups. These analyses indicate that random assignment of subjects to experimental and control groups was not entirely effective in making the groups equivalent, and that statistical 
Table I. Means, Ranges, Standard Deviations, and Numbers of Respondents for Dependent Variable Measures by Interview

\begin{tabular}{|c|c|c|c|c|c|}
\hline Measure & Interview & $N$ & Range & $\overline{\bar{X}}$ & SD \\
\hline Potassium level ( $\mathrm{mEq} /$ liter) & $\begin{array}{l}\mathrm{T}_{1} \\
\mathrm{~T}_{2} \\
\mathrm{~T}_{3}\end{array}$ & $\begin{array}{r}111 \\
94 \\
85\end{array}$ & $\begin{array}{l}3.50-6.20 \\
3.80-5.80 \\
3.80-5.90\end{array}$ & $\begin{array}{l}4.85 \\
4.85 \\
4.94\end{array}$ & $\begin{array}{l}0.55 \\
0.47 \\
0.44\end{array}$ \\
\hline $\begin{array}{l}\text { Weight gain between dialysis } \\
\text { treatments }(\mathrm{kg})\end{array}$ & $\begin{array}{l}\mathrm{T}_{1} \\
\mathrm{~T}_{2} \\
\mathrm{~T}_{3}\end{array}$ & $\begin{array}{r}111 \\
93 \\
82\end{array}$ & $\begin{array}{l}0.67-5.22 \\
0.64-4.26 \\
0.61-4.42\end{array}$ & $\begin{array}{l}2.69 \\
2.47 \\
2.48\end{array}$ & $\begin{array}{l}0.94 \\
0.77 \\
0.76\end{array}$ \\
\hline $\begin{array}{l}\text { Perceived susceptibility to } \\
\text { sequelae of noncompliance with } \\
\text { dietary restrictions }\end{array}$ & $\begin{array}{l}\mathrm{T}_{1} \\
\mathrm{~T}_{2} \\
\mathrm{~T}_{3}\end{array}$ & $\begin{array}{r}111 \\
91 \\
84\end{array}$ & $\begin{array}{l}3-7 \\
4-7 \\
2-7\end{array}$ & $\begin{array}{l}5.64 \\
6.32 \\
6.08\end{array}$ & $\begin{array}{l}0.92 \\
0.81 \\
1.08\end{array}$ \\
\hline $\begin{array}{l}\text { Perceived susceptibility to } \\
\text { sequelae of noncompliance with } \\
\text { limiting fluid intake }\end{array}$ & $\begin{array}{l}\mathrm{T}_{1} \\
\mathrm{~T}_{2} \\
\mathrm{~T}_{3}\end{array}$ & $\begin{array}{r}108 \\
92 \\
81\end{array}$ & $\begin{array}{l}3-7 \\
4-7 \\
3-7\end{array}$ & $\begin{array}{l}5.97 \\
6.50 \\
6.32\end{array}$ & $\begin{array}{l}0.92 \\
0.74 \\
0.89\end{array}$ \\
\hline $\begin{array}{l}\text { Perceived severity of sequelae } \\
\text { of noncompliance with dietary } \\
\text { restrictions }\end{array}$ & $\begin{array}{l}\mathrm{T}_{1} \\
\mathrm{~T}_{2} \\
\mathrm{~T}_{3}\end{array}$ & $\begin{array}{r}111 \\
91 \\
84\end{array}$ & $\begin{array}{l}2-7 \\
3-7 \\
3-7\end{array}$ & $\begin{array}{l}5.61 \\
6.06 \\
6.07\end{array}$ & $\begin{array}{l}1.08 \\
0.86 \\
0.98\end{array}$ \\
\hline $\begin{array}{l}\text { Perceived severity of sequelae } \\
\text { of noncompliance with limiting } \\
\text { fluid intake }\end{array}$ & $\begin{array}{l}\mathrm{T}_{1} \\
\mathrm{~T}_{2} \\
\mathrm{~T}_{3}\end{array}$ & $\begin{array}{r}108 \\
92 \\
81\end{array}$ & $\begin{array}{l}4-7 \\
4-7 \\
3-7\end{array}$ & $\begin{array}{l}6.12 \\
6.44 \\
6.40\end{array}$ & $\begin{array}{l}0.84 \\
0.70 \\
0.80\end{array}$ \\
\hline $\begin{array}{l}\text { Beliefs about the benefits } \\
\text { of the diet }\end{array}$ & $\begin{array}{l}\mathrm{T}_{1} \\
\mathrm{~T}_{2} \\
\mathrm{~T}_{3}\end{array}$ & $\begin{array}{r}111 \\
92 \\
83\end{array}$ & $\begin{array}{l}3-7 \\
2-7 \\
2-7\end{array}$ & $\begin{array}{l}5.81 \\
5.98 \\
5.96\end{array}$ & $\begin{array}{l}1.04 \\
1.08 \\
1.04\end{array}$ \\
\hline $\begin{array}{l}\text { Beliefs about the benefits } \\
\text { of limiting fluid intake }\end{array}$ & $\begin{array}{l}T_{1} \\
T_{2} \\
T_{3}\end{array}$ & $\begin{array}{r}101 \\
91 \\
75\end{array}$ & $\begin{array}{l}3-7 \\
3-7 \\
3-7\end{array}$ & $\begin{array}{l}6.00 \\
6.23 \\
6.29\end{array}$ & $\begin{array}{l}0.88 \\
0.83 \\
0.94\end{array}$ \\
\hline $\begin{array}{l}\text { Barriers associated with } \\
\text { following dietary } \\
\text { restrictions }\end{array}$ & $\begin{array}{l}\mathrm{T}_{1} \\
\mathrm{~T}_{2} \\
\mathrm{~T}_{3}\end{array}$ & $\begin{array}{r}111 \\
93 \\
86\end{array}$ & $\begin{array}{l}0-7 \\
0 \sim 6 \\
0-6\end{array}$ & $\begin{array}{l}2.82 \\
2.23 \\
2.05\end{array}$ & $\begin{array}{l}1.68 \\
1.46 \\
1.54\end{array}$ \\
\hline $\begin{array}{l}\text { Barriers associated with } \\
\text { limiting fluid intake }\end{array}$ & $\begin{array}{l}T_{1} \\
T_{2} \\
T_{3}\end{array}$ & $\begin{array}{r}108 \\
94 \\
83\end{array}$ & $\begin{array}{l}0-5 \\
0-5 \\
0-4\end{array}$ & $\begin{array}{l}1.74 \\
1.55 \\
1.24\end{array}$ & $\begin{array}{l}1.28 \\
1.13 \\
1.09\end{array}$ \\
\hline
\end{tabular}

controls would be necessary to eliminate those initial differences between groups which might bias the conclusions reached about the effects of the intervention programs. However, comparisons of the experimental groups on sociodemographic, medical history, and belief variables showed no significant differences between groups.

Analysis of covariance was used to evaluate the effects of the intervention programs. To adjust for the initial group differences, the baseline measure of patients' average WGs was included as a covariate in all analyses which dealt with fluid limit compliance and with health beliefs about fluid limit compliance. Similarly, patients' baseline SPLs were employed as a 
covariate in all analyses dealing with dietary compliance and with health beliefs about dietary compliance. All means to be presented have been adjusted for these covariables. Scheffe's multiple comparison procedure was used to evaluate pairwise differences between experimental groups.

\section{Dietary Compliance}

Using the criterion level set by medical staff of average SPL less than $5.5 \mathrm{mEq} /$ liter as an indicator of compliance to the diet regimen, $86 \%$ of the study group are classified as compliant at $T_{1}$. Over $90 \%$ of the study patients are classified as compliant to the diet regimen at $\mathrm{T}_{2}$, and $86 \%$ are classified as compliant at $T_{3}$.

As can be seen in Fig. 2, the mean SPLs at $T_{2}$ are lower for the three intervention groups than for the control group. Compared to patients in the control group, there is a significant difference in the mean SPL for patients in the weekly telephone contact group $[F(1,50)=10.51, P<0.05]$ and for patients in the behavioral contract group $[F(1,46)=8.82, P<0.05]$. At $\mathrm{T}_{3}$, however, there are no significant differences in mean SPLs among the experimental groups.

\section{Fluid Limit Compliance}

Based on a compliance criterion level of average WG less than $3.0 \mathrm{~kg}$ between dialysis treatments, $59 \%$ of the patients are classified as compliant at $T_{1}, 73 \%$ are classified as compliant at $T_{2}$, and $75 \%$ are classified as compliant at $T_{3}$.

As shown in Fig. 3, the mean WG between dialysis treatments at $T_{2}$ is lower for each of the intervention groups than for the control group. However, only the patients in the group "behavioral contract with a family member or friend" have a significantly lower mean WG than patients in the control group $[F(1,40)=7.82, P<0.05]$. At $\mathrm{T}_{3}$, there are no significant differences in mean WGs among the experimental groups. However, patients in the two behavioral contract interventions have average WGs which are $13 \%$ lower than those of patients in the control group and are $9 \%$ lower than those of patients in the weekly telephone contact group.

\section{Health Beliefs and Compliance}

Patients' health beliefs were assessed at each of the three questionnaire administrations. Correlations of the belief measures with compliance levels at $T_{1}$ are presented in Table II. Only patients' estimate of the number of 

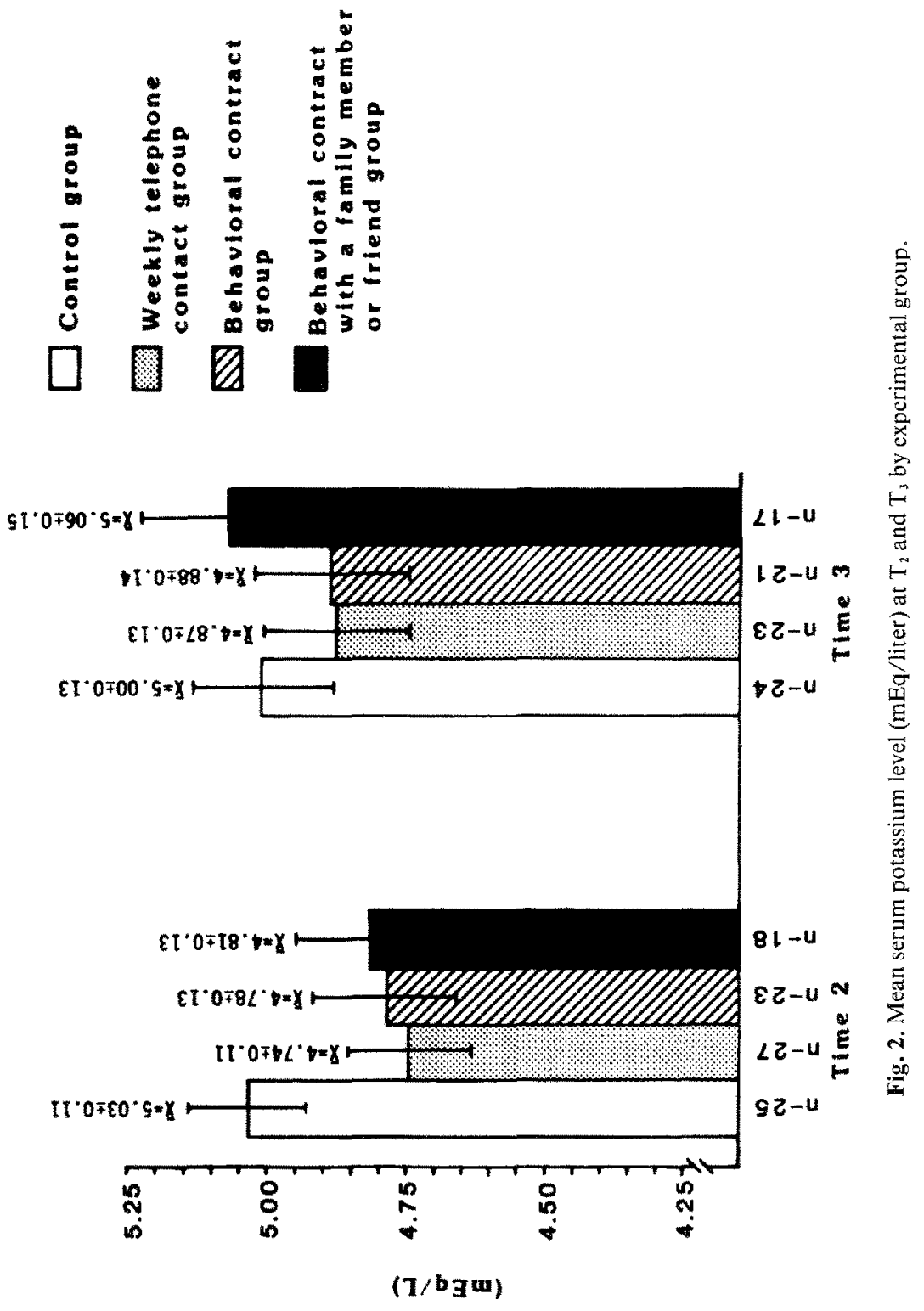

jonat unjesejod undas ueaw 

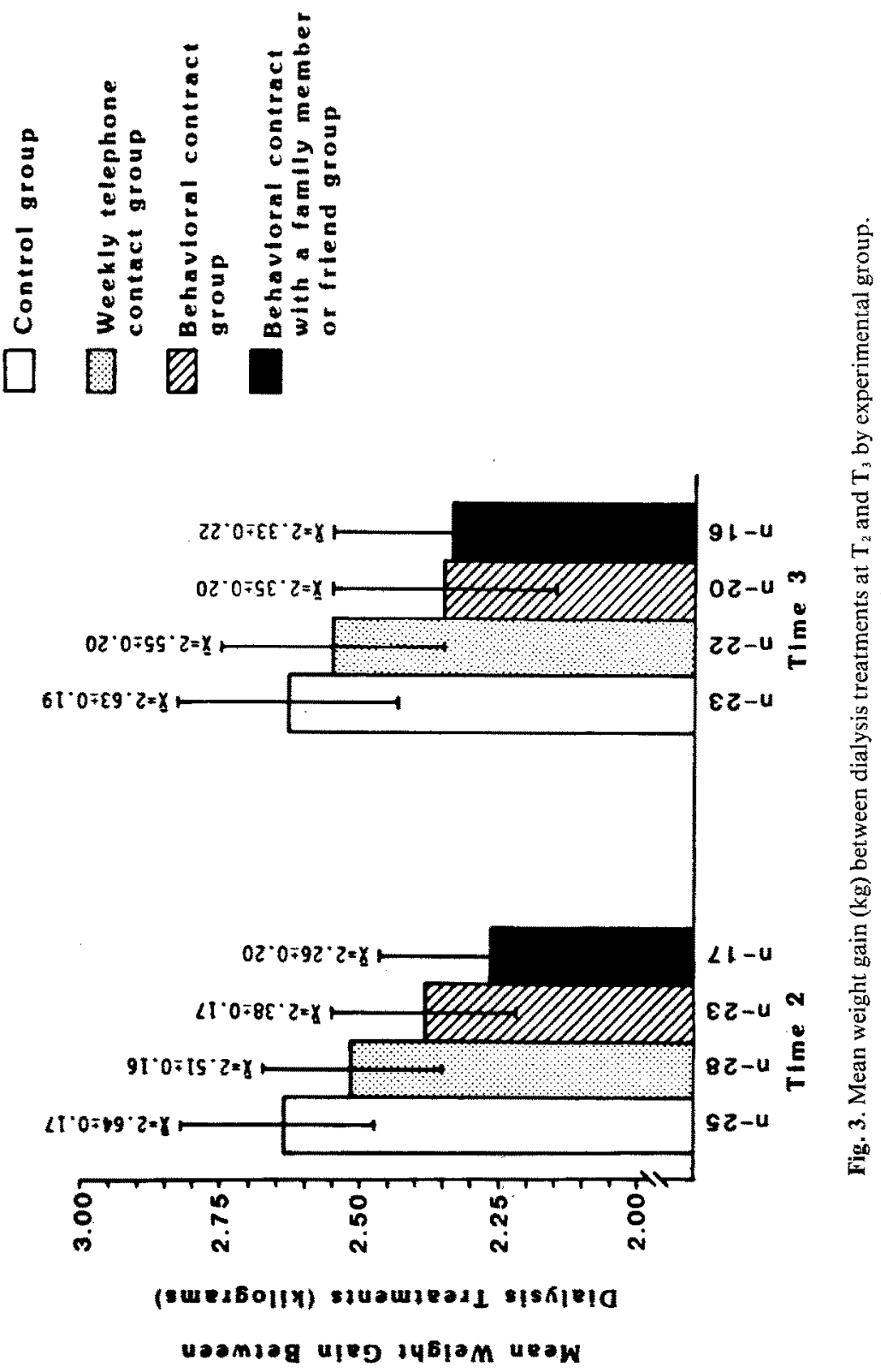
Table II. Correlations (Product Moment) of Belief Indices and Compliance Measures at Time 1

\begin{tabular}{lcc}
\hline & \multicolumn{2}{c}{ Compliance measures } \\
\cline { 2 - 3 } Index & $\begin{array}{c}\text { Serum potassium } \\
\text { levels }\end{array}$ & Weight gain \\
\hline $\begin{array}{l}\text { Perceived susceptibility to } \\
\text { sequelae of noncompliance }\end{array}$ & 0.09 & 0.01 \\
Perceived severity of & $(111)^{a}$ & $(111)$ \\
$\quad$ sequelae of noncompliance & 0.04 & -0.05 \\
Belief in the benefits of & $(111)$ & $(111)$ \\
the regimen & 0.14 & -0.04 \\
Barriers interfering with & $(111)$ & $(101)$ \\
following the regimen & $-0.23^{*}$ & $-0.27^{*}$ \\
\hline
\end{tabular}

${ }^{a} N$ s indicated in parentheses.

$* P<0.05$.

barriers which interfere with their ability to comply with either the diet or the fluid limit were significantly related to compliance.

\section{Experimental Treatments and Health Beliefs}

Table III presents the mean health belief scores at $T_{2}$ and $T_{3}$ for each experimental group. As expected, there is a trend for patients in the weekly telephone contact group to report higher levels of perceived susceptibility and perceived severity than do patients in the other experimental groups. The differences in mean levels of susceptibility and severity between patients in the weekly telephone group and the other experimental groups are greater for the measures pertaining to the diet than for the measures dealing with the fluid level. However, none of the differences between experimental groups is statistically significant.

There are no significant differences between experimental groups for either the $T_{2}$ or the $T_{3}$ comparisons of patients' beliefs about the benefits of the prescribed regimen and comparisons of the number of barriers reported by patients as interfering with their ability to comply with the regimen.

\section{DISCUSSION}

Improvements in compliance with a regimen restricting foods high in potassium and limiting fluid intake between dialysis treatments were found to be related to the intervention programs at $T_{2}$, with little difference among the different intervention programs tested. The effects of the interventions 


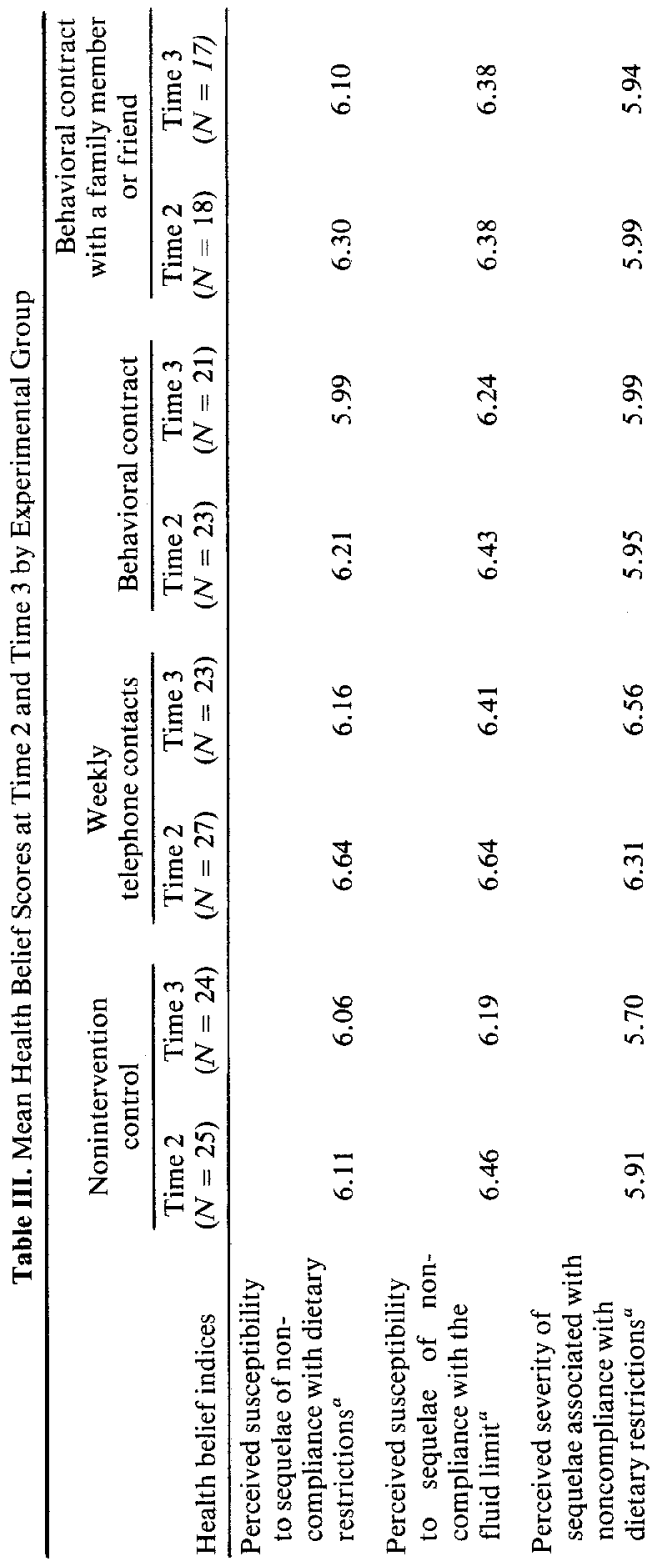




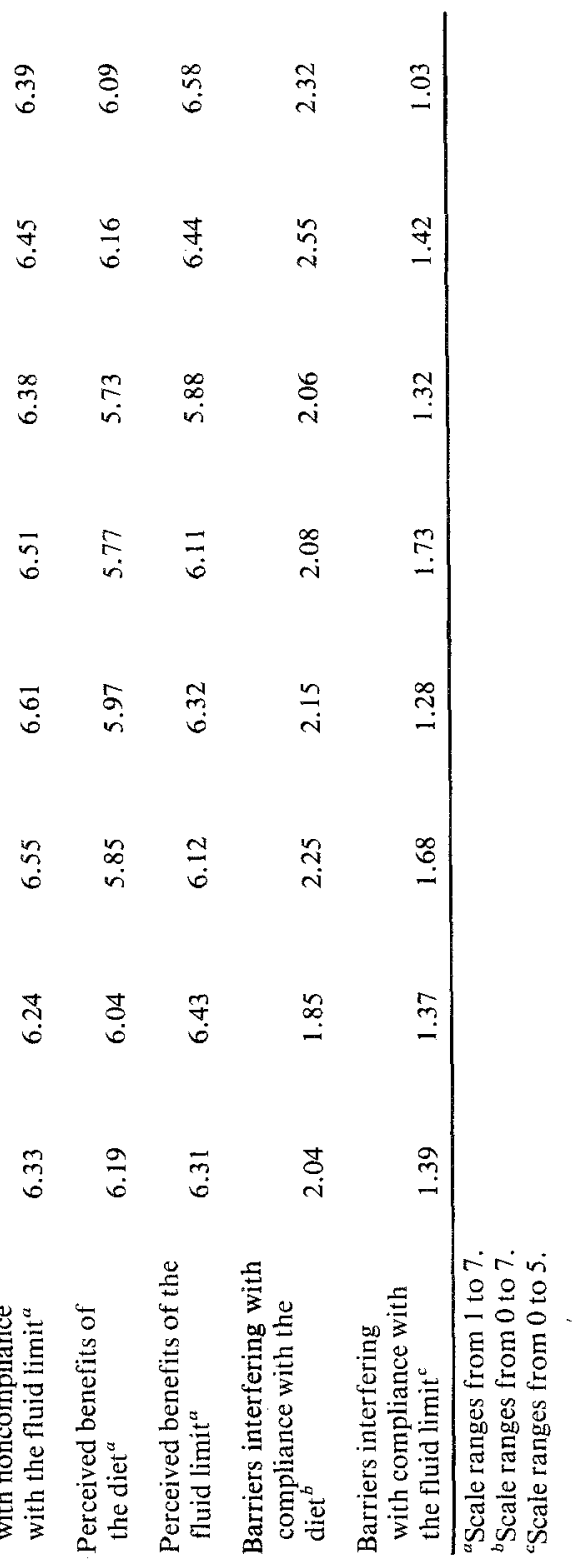


tapered off to preintervention levels once the interventions were discontinued. Thus, with regard to the duration of the interventions, our findings suggest a need for continuous follow-up with patients.

Health beliefs were generally not predictive of compliance. Only the number of barriers reported by patients as interfering with their compliance was significantly associated with adherence to therapy. Thus, it seems reasonable to believe that, even if beliefs had been modified by the intervention programs, this would have had little impact on compliance. As it turned out, the interventions had little effect on changing patients' beliefs about their diet and/or fluid limit. The fact that the weekly telephone contact intervention was effective in increasing compliance levels despite the failure of health beliefs to be correlated with compliance indicates that there are other features of this intervention which influence patients' compliance behavior.

From pattern of results, it appears that the nature of the intervention itself cannot be seen as a key element. All three interventions had an effect, and at about the same level. One interpretation is that increased contact or attention by the nurses was sufficient for a change in adherence. The mechanism through which the effect occurred is not clear from the study, except that belief change, of the sort assessed, did not appear to be necessary. Another interpretation is that the changes observed at $T_{2}$ were due to specific aspects of the interventions but that many alternative modes for initiating change are effective.

The return from change at $\mathrm{T}_{3}$ is dramatic and fits with the results found in other studies (Wilber and Barrow, 1969; McKenney et al., 1977; Magrab and Papadopoulou, 1978). Once an intervention ends, behavior reverts to the preintervention level. This finding suggests that the effectiveness of the particular interventions utilized depends on factors external to the individual-whether simple conformity to an authority, identification with the nurse, or response to a tangible reward. Future research must therefore focus attention on the mechanisms through which behavior change occurs and on ways in which behavior change can be maintained.

\section{REFERENCES}

Abram, H. S., Moore, G. L., and Westervelt, F. B. (1971). Suicidal behavior in chonic dialysis patients. Am. J. Psychiat. 127: 1119-1204.

Anderson, C. F., Nelson, R. A., Margie, J. D., Johnson, W. J., and Hunt, J. C. (1973). Nutritional therapy for adults with renal disease. JAMA 22: 68-72.

Blackburn, S. L. (1977). Dietary compliance of chronic hemodialysis patients. J. Am. Diet. Assoc. 70: 31-37.

Borkman, T. S. (1976). Hemodialysis compliance: The relationship of staff estimates of patient's intelligence and understanding to compliance. Soc. Sci. Med. 10: 385-392. 
Burton, B. T. (1974). Current concepts of nutrition and diet in diseases of the kidney. J. Am. Diet. Assoc. 65: 623-626.

De-Nour, A. K., and Czaczkes, J. W. (1972). Personality factors in chronic hemodialysis patients causing noncompliance with medical regimens. Psychosom. Med. 34: 333-334.

Haefner, D. P., and Kirscht, J. P. (1970). Motivational and behavioral effects of modifying health beliefs. Publ. Health Rep. 55: 478-484.

Hartman, P. E., and Becker, M. H. (1978). Noncompliance with prescribed regimen among chronic hemodialysis patients: A method of prediction and educational diagnosis. Dial. Transplant. 7: 978-989.

Hickey, K. M. (1972). Impact of kidney disease on patient, family and society. Soc. Casework 53: 391-393.

Kirscht, J. P., Becker, M. H., Haefner, D. P., and Maiman, L. A. (1978). Effects of threatening communications and mothers' health beliefs on weight change in obese children. $J$. Behav. Med. 1: 147-157.

Magrab, P. R., and Papadopoulou, Z. L. (1978). The effect of a token economy on dietary compliance for children on hemodialysis. J. Appl. Behav. Anal. 10:573-578,

McKenney, J., Slining, J. M., Henderson, H. R., Devins, D., Barr, M., Stern, M. P., Farquhar, J. W., Maccoby, N., and Russell, S. H. (1977). The effects of clinical pharmacy services on patients with essential hypertension. Circulation 48: 1104-1111.

Meldrum, M. W., Wolfram, H. G., and Rubini, M. E. (1968). The impact of chronic hemodialysis upon the socio-economics of a veteran patient group. J. Chron. Dis. 21: 37-52.

Neff, S., Baez, A., Slifkin, R., and Schupak, E. (1973). Outpatient dialysis. Arch. Intern. Med. 131: 717-721.

Pendras, J. P., and Erickson, R. V. (1966). Hemodialysis: A successful therapy for chronic uremia. Ann. Intern. Med. 64: 293-311.

Penick, S. B., Filion, R., Fox, S., and Stunkard, A. J. (1971). Behavior modification in the treatment of obesity. Psychosom. Med. 33: 49-55.

Reid, E. L., and Morgan, R. W. (1979). Exercise prescription: A clinical trial. Am. J. Publ. Health 69: 591-595.

Retan, J. W., and Lewis, H. Y. (1965). Repeated dialysis of indigent patients for chronic renal failure. Ann. Intern. Med. 64: 284-292.

Shea, E. J., Bogdan, D. F., Freeman, R. B., and Schreiner, G. E. (1965). Hemodialysis for chronic renal failure. IV. Psychological considerations. Ann. Intern. Med. 62: 558-563.

Steckel, S. B., and Swain, M. (1977). The use of written contracts to increase adherence. Hospitals 51: 81-84.

Stunkard, A. J. (1972). New therapy for the eating disorders: Behavior modification of obesity and anorexia nervosa. Arch. Gen. Psychiat. 26: 391-398.

Weisenberg, M., Kegeles, S. S., and Lund, A. K. (1980). Children's health beliefs and acceptance of a dental preventive activity. J. Health Soc. Behav. 21: 59-74.

Wilber, J. A., and Barrow, J. B. (1969). Reducing elevated blood pressure-experience found in a community. Minn. Med. 52: 1303-1305. 